Bol. Acad. peru. leng. 47. 2009 (143-147)

\title{
MEDALLA DE HONOR DEL CONGRESO DE LA REPÚBLICA A FRANCISCO MIRÓ QUESADA CANTUARIAS
}

\author{
María Luisa Rivara de Tuesta \\ Universidad Nacional Mayor de San Marcos
}

Sr. Dr. Javier Velásquez Quesquén, Presidente del Congreso

Sra. Dra. Martha Hildebrandt

Sr. Dr. Francisco Miró Quesada Cantuarias

Sr. Dr. Francisco Miró Quesada Rada

Señoras y señores.

La conferencia que con ocasión de esta Ceremonia de Condecoración y reconocimiento del Congreso de la República, ha pronunciado el maestro Francisco Miró Quesada, nos ilustra sobre su vida y su obra como filósofo racionalista-humanista y la relación de estos dos importantes conceptos, la razón y el humanismo con la justicia.

¿Es la razón la que decide nuestra reflexión, nuestro actuar y nuestro hablar? ¿Es el hombre que integra nuestra realidad social-humana, compleja por ser pluriétnica, plurilingüe y pluricultural, es ese hombre un fin en sí mismo, y no el instrumento de nuestro interés personal o de grupo dominante? Estas dos importantes y significativas preguntas conducen a una deducción lógica: El ejercicio primordial de la razón y el humanismo nos acercan y conducen, con absoluta certeza, al logro de una sociedad más humana y más justa. 
Y es que el ejercicio filosófico peruano tiene en Francisco Miró Quesada a su más destacado exponente, no sólo por ser conocedor de las corrientes del filosofar actual sino porque ha contribuido como intelectual e investigador a enriquecer nuestro patrimonio reflexivo con obras de carácter riguroso y sistemático sobre temas epistemológicos y lógicos. Su labor de difusión de sistemas y doctrinas filosóficas es ampliamente conocida, sobre todo en lo que respecta a la corriente fenomenológica y a la lógica simbólica. La epistemología de la matemática, la filosofía de las matemáticas, la filosofía de la ciencia y otras disciplinas se han visto enriquecidas con su obra escrita y su labor de enseñanza en nuestros medios universitarios. Su aporte a la filosofía ha sido reconocido por la comunidad filosófica mundial al ser designado Presidente de la Federación Internacional de Sociedades de Filosofía para el período 1993-1998. Ha participado en congresos nacionales e internacionales de filosofía, en simposios, en coloquios y otras reuniones filosóficas y científicas, por cuya participación se le ha otorgado premios, condecoraciones y medallas de: Alemania, Brasil, Colombia, Chile, Estados Unidos, Francia, la OEA y Polonia.

De un lado se da en Francisco Miró Quesada esta obra de difusión estrictamente filosófica que él ha cumplido a cabalidad, de otro lado tenemos una creación orientada hacia el examen y la búsqueda de soluciones teóricas a los problemas de nuestra praxis política, una realización como teórico de Acción Popular. Su Manual ideológico. "El Perú como doctrina”.

Consideramos, sin embargo, que se da una tercera dimensión en nuestro pensador, que es la que responde a la necesidad de hacer desde América y con motivo de América una auténtica y creativa reflexión filosófica, desde esta perspectiva debemos referirnos a su contribución latinoamericanista. Ha escrito dos obras ampliamente conocidas: Despertar y proyecto del filosofar latinoamericano y Proyecto y realización del filosofar latinoamericano. En su reflexión latinoamericanista, debemos puntualizar que, en si mismas constituyen resúmenes históricos del proceso filosófico en nuestro continente y permiten un conocimiento esencial de sus ideas en lo que respecta al análisis interpretativo del proceso que conduce a 
la formación de lo que él denomina "tercera generación" de filósofos y su toma de conciencia de una nueva forma de filosofar sobre nuestra propia realidad. Ambas obras se dan intrínsecamente unidas; en la primera se ocupa de los "patriarcas" y los "forjadores" y de su proyecto de un filosofar auténtico, proyecto que influye fundamentalmente nuestro proceso filosófico hasta presentarse el momento de su bifurcación -que se produce por la década del sesenta del siglo pasado- en filósofos "afirmativos" y "asuntivos"; y en la segunda se ocupa principalmente de los logros alcanzados por los filósofos que denomina asuntivos.

Son filósofos "afirmativos" los que comienzan a pensar desde un logos entendido como palabra y razón, aportando su reflexión para la solución de los problemas de nuestra América y son "asuntivos" los que asumen la filosofía como seguidores de la concepción occidental actual.

Sería rebasar los marcos del presente comentario exponer en detalle los ensayos, que en forma de ponencias o artículos, ha elaborado Francisco Miró Quesada en relación con la filosofía latinoamericana, sobre todo en lo que respecta a la singular postulación de una Filosofía de la Liberación.

Se trataría de mostrar la continuidad y penetración en una temática que vislumbra como importante y significativa en lo que denomina los albores de un proyecto de filosofar auténticamente latinoamericano, reiterar que una y otra vez aun cuando esté refiriéndose a temáticas de otra índole, la reflexión de filósofo afirmativo sobre nuestra "liberación" aparece y se va haciendo en esas apariciones esencialmente consubstancial hasta adquirir un espacio singular y propio como expresión de la reflexión latinoamericana.

Miró Quesada frente al proceso ideológico de nuestra América dependiente y subdesarrollada, encuentra que lo que caracteriza el proceso histórico de Latinoamérica durante el siglo XX es que América se dirige a la autenticidad cultural enfrentándose a la moda europea y que reaccionará afirmando la necesidad de realizar sus propias creaciones y ésto como el único medio de enfrentarnos auténticamente a nuestros propios 
problemas a fin de encontrar las soluciones adecuadas. Se trata de un proceso de asimilación auto afirmativo, de experimentación auténtica de la creación occidental para su utilización dentro de nuestra propia situación cultural.

Comenzamos, haciendo historia de nuestro transcurrir filosófico e ideológico, a desentrañar el sentido de nuestra historia como un afán consciente y racional de la liberación humana porque para poder encauzar nuestro proceso de liberación, tenemos que conocer nuestra historia, y si la esencia del latinoamericano consiste en afirmar su ser para ser reconocido en la plenitud de su humanidad, es evidente que la única manera de lograr este reconocimiento es siendo libre, y mientras los centros mundiales de poder sigan dominando a Latinoamérica se hará imposible que podamos ser nosotros mismos. Por eso debemos romper todos los vínculos de sometimiento que nos atan a los centros de dominación, inclusive, los mecanismos más sutiles.

El análisis filosófico del significado de la liberación lo ha llevado al planteamiento de un modelo social, modelo basado en el humanismo, ya que el punto de partida de toda esta notable evolución, es la necesidad de afirmarnos como seres humanos. La filosofía de lo americano ha desembocado a través de la conquista de la autenticidad de nuestro pensamiento en un humanismo. América Latina se concibe a sí misma como exigencia de plenitud humana, plenitud que sólo puede lograrse a través de la plenitud de todos los hombres. A través de la filosofía de lo americano, igualmente, el pensamiento procediendo auténticamente, descubrió que nuestra realidad es inhumana y que debe ser cambiada.

El análisis racional coincide así con la exigencia de liberación, y en este proceso, la filosofía de lo americano ha colocado a la filosofía en su verdadera función: "es la expresión suprema de la razón humana, que es, a su vez, instrumento supremo de liberación" "La filosofía de lo americano: treinta años después”, en Latinoamérica, N. ${ }^{\circ} 10,1977$, pp. 19-23). Sin embargo, no habrá integración cultural mientras no sean incorporados a la cultura las masas marginadas de la cultura, los hombres exiliados de su propia patria, los desterrados en su propio suelo. 
Para Francisco Miró Quesada el solo hecho de proponer una filosofía de la liberación plantea el problema de fundamentar la posibilidad liberadora de la filosofía desde la racionalidad ("Prólogo", en Antología de filosofía política y filosofía de la historia, 1988, 7 p.).

Nosotros - dice- estamos convencidos de que la filosofía cuando se practica auténticamente, es decir, cuando se utiliza la razón para intentar resolver problemas y para elaborar y refutar teorías, conduce necesariamente hacia una praxis de liberación. Porque la razón, por esencia, es lo que se opone a la fuerza. El que decide dedicarse a la filosofía, adquiere un compromiso consigo mismo: proceder de acuerdo a la razón. Y la razón es lo opuesto de la arbitrariedad, en consecuencia,... tiene que oponerse... a todo tipo de opresión (6).

En conclusión, para nuestro homenajeado la Filosofía de la Liberación, aunque ha dicho ya muchas cosas, tiene aún muchas más que decir, y como toda expresión filosófica, surgida auténticamente de nuestra realidad, está abierta a su propio proyecto de realización, en el cual nuestro filósofo - estoy segura- seguirá colaborando y contribuyendo a su edificación como hasta ahora lo ha hecho y lo evidencia esta apretada síntesis de su aporte filosófico.

Lima, 09 de diciembre de 2008. 